material of such a character as to destroy its efficiency. Its use for these purposes is, however, very much restricted, because we have no means of disposing of it, except through lead pipes.

Objections have been made to it because of its poisonous character. The danger of poisoning, however, is very slight. 'The solutions employed are very dilute, and its taste is sufficiently disagreeable to attract attention before an amount sufficient to do any injury has been taken. If the solutions are colored, the danger of mistakes is much lessened. The same objection may be made with equal reason against all substances which we now recognize as disinfectants. Care is necessary in the employment of all of them, and those entrusted with their use should be informed of their properties, that all necessary precautions may be taken.

There is, however, one process of disinfection with corrosive sublimate to which this objection may with some reason be made. I refer to its use for the disinfection of streets, for which purpose it has been employed by the Board of Health of Boston for the past two years or more. If its use for this purpose is continued, the time cannot be far distant when the beds of the streets will become saturated with various compounds of mercury. All of these, so far as we have any knowledge of them, are violent poisons. Is any danger to be apprehended from continually inhaling or swallowing, month after month, dust loaded with compounds of mercury? This is a question deserving serious consideration at the hands of the Board of Health. While not claiming that the process is positively a dangerous one, I believe it is one which involves some risks, and one which it is advisable, therefore, to discontinue.

UTERINE DISPLACEMENTS AND THEIR INFLUENCE ON THE GENERAL NERVOUS SYSTEM. ${ }^{\circledR}$

BY FRANCIS H. DAVENPORT, M.D.

UTERINe displacements have from the earliest times about which we have any medical knowledge been recognized as existing, and as giving rise to disturbances both general and local. It is probable that prolapse and procidentia, as being malpositions which would most quickly and surely be seen, were the first to be diagnosticated and treated. Later, as the vaginal examination became perfected, would follow the forward and backward displacements, reserving for these days of gynæcological enlightenment the recognition of the more refined shades of departure from the normal, which have filled our text books with subvarieties, and for whose relief a legion of pessaries has been invented.

The impetus which has been given to the study of this branch of medicine in the last twenty-five or thirty years has resulted in placing a great deal that is of value on a sound basis. With regard to the special branch of uterine disease which is the subject of this paper, the following may be said : We have learned to diagnosticate the various malpositions to which the uterus is liable, and the tactus eruditus is now seeking new worlds to conquer. Tubes and ovaries whose recognition by a large proportion of practising physicians is still a matter of considerable difficulty are pal-

${ }^{1}$ Read before the Massachusetts Medical Society, June 12, 1888, and recommended for publication by the Society. pated by the trained gynæcologist, and their pathological changes diagnosticated with wonderful ease. The more remote and insignificant structures of the pelvis are now trying in vain to elude the searching finger of the specialist; and in one of the latest text books minute and lengthy rules are given for finding not only the round ligament and ureter, but even for differentiating the various muscles of the pelvic floor, and palpating the pelvic arteries and nerves.

The chapter on the diagnosis of displacements may in a certain sense be said to be closed. So, too, with the mechanical treatment of these disorders. Necessity is the mother of invention, and the skill and perseverance of the gynæcologist in overcoming the diffculties he has had to contend with, have resulted in the multiplication of pessaries of all forms from the external to the intra-uterine, and of substances as various as ingenious, to meet all possible varieties. Slight modifications will continue to appear, but they will be on the lines already marked out, and will in all probability embody no new principle. It is to my mind a fair indication of the feeling which may be supposed to govern the question of treatment in the small proportion of cases which do not show themselves amenable to the mechanical devices alluded to, that progress is in the direction of operative measures, and that too of a bolder character than would have been dreamed of twenty or even ten years ago. Who, for instance, twenty years ago would have thought in his wildest moments of performing laparotomy and suturing the fundus uteri to the abdominal wall to cure an obstinate retroflexion? Yet that has been repeatedly done. It is an outcome to be sure of the feeling of security with regard to opening the abdominal cavity which the splendid results of our leading specialists have developed. Yet still other indications, less striking perhaps, but showing the same tendency, are the Alexander operation of shortening the round ligaments, Sänger's bold procedure of forcibly separating adhesions of the uterus to adjacent parts under ether, or Byford's proposition to shorten the sacra-uterine ligaments by an operation from the vagina.

While such questions as these are, as I have said, practically settled, it is a beneficent law which holds good in any department of human knowledge that it cannot be exhausted. Certain outposts are taken and occupied, and the scene of the conflict shifts to new ground. We know the course which the blood takes in its rapid circulation through the body. We busy ourselves now with counting the millions and billions of white and red blood corpuscles, and noting their varying proportions in disease, or discussing the microscopical character of the membrane which forms the coat of the capillaries. So the question concerning displacements, about which doubt exists to-day, and which are the subjects of discussion, are on entirely different lines from those we have mentioned above.

Curiously enough, one question which it would seem would naturally be the first to be settled, is only recently being met with any unanimity of sentiment. I refer to the normal position of the uterus. It is begging the question to affirm, as some writers do, that an organ, suspended in the pelvis between other organs liable to such temporary variations of size as the bladder and rectum, can have no normal position. On the other hand, it is manifestly absurd to judge a freely movable organ by the same rules as we would a spleen or kidney, and make any deviation from an arbitrary fixed 
standard a malposition. The truth seems to lie between, and the most accurate observers now recognize a normal position of the uterus which varies within certain bounds according to the condition of the adjacent pelvic viscera.

I have said that the question of the mechanical treatment of displacements was practically settled, meaning by that that where such treatment was indicated, the principles on which it would be carried out were essentially known. There still exists, however, great difference of opinion as to the advisability or necessity of such treatment at all. Some writers, a respectable minority at least, maintain that displacements of the uterus very seldom give rise to symptoms, and that when they do general treatment is preferable to local. Still others claim that they are much more often the cause than the result of general conditions, and that not only is it useless to ignore mechanical treatment, but that the best results are obtained by such local treatment either alone or primarily.

These differences of opinion are based upon the different views which are held with regard to the dependence of one upon the other in the question of causation, and their subsequent reaction upon each other. Let me make this clearer by illustration. We find in a given case a malposition of the womb. With it is associated a debilitated state of the nervous system, which shows itself in the protean ways that are so familiar to us under the convenient but vague term of neurasthenia. There is now a problem to be solved in order to arrive at such a correct understanding of the case, that we shall be able to treat it successfully. What has been the sequence of events in this particular instance? Has the general health begun to suffer, the nutrition become impaired, the muscular system weakened, fat absorbed, and as a result the natural supports of the uterus become relaxed, and thus allowed of a version or flexion? Or, on the other hand, has the uterus become displaced, has congestion resulted, followed by a low grade of inflammation, has this begun to react upon the nervous system, and finally resulted in the more or less complete loss of tone which we find in these cases? If we claim that the first hypothesis is correct, our course is plain. Build up the nervous system by rest and tonics, make fat and blood by forced feeding, and as the body becomes better nourished, and the muscular system grows stronger, the uterus will right itself.

On the other hand, if we take the starting-point to be the displacement, our rational plan is to restore the uterus to its normal position, relieve the congestion, diminish the nervous strain, and our patient is cured.

There are to-day firm, I had almost said bigoted, adherents of both these opinions. There are men who make light of the local symptoms of their neurasthenic patients, who claim that treatment of the genital organs rarely does good, and often does harm, and who concentrate all their attention on general treatment. So, too, there are others who refer all these complex and remote symptoms to some lesion of the pelvic viscera, and are content to treat those exclusively. As a natural and almost inevitable result of circumstances, it follows that those who devote themselves largely to gynæcological practice should more often err in the last-named direction, while those who from the character of their practice or from preference see few such cases should fail to give these symptoms their proper significance.
That neither of these extreme views is correct is self-evident. It is, however, insufficient to state in a general way that the advocates of both systems go too far. Little has been done unless such practical considerations are urged and demonstrated, as will set forth in a clear light the true relations which prevail between disorders in the genital sphere, and general nervous symptoms. It will be the object of this paper, if possible, to do this.

There are several questions to be discussed. In the first place we are met at the outset by the inquiry which suggests itself always in considering this subject, is the relation between the genital organs and the whole nervous system so peculiar, that disorders of the latter more often follow disease of the former, than is the case with other organs of the body? 'The ancients believed it to be so when they attributc $d$ to the influence of the womb those nervous manifentations which under the name of hysteria we recognize as a common symptom of a debilitated nervous condition. We now know that hysteria is not necessarily associated with uterine disease, that in fact it occurs in men, yet its preponderance in woman is a suggestive fact. Granted that a woman's nervous system is naturally weaker than a man's, may the cause not lie in the fact that her generative organs during their period of functional activity call for a greater expenditure of nervous force even when in health than any other organ or set of organs? If this is so in health, how much more potent must be their influence when diseased. That such nervous phenomena as we generally call hysteria or the more pronounced condition of nervous debility known as neurasthenia almost exclusively occur between the years of puberty and the menopause, confirms the opinion that there is in the majority of cases a more than chance relation between the disorders of the genital functions and the general nervous disturbance.

The clinical experience of those who have had the largest opportunities for observing these cases, will, I am confident, be confirmatory of this opinion.

There are, undoubtedly, certain classes of pelvic disease which more than others predispose to coincident nervous wear and tear. The amount of pain which accompanies the lesion is one of the criteria by which we judge of the probable effect upon the nervous system. We, therefore, find certain forms of ovarian disease accompanied by dysmenorrhœa very frequently associated with nervous debility. This rule is not absolute, however, for cancer with its gnawing pain does not affect the nervous system in the way that $I$ am describing. It saps the strength and diminishes the vital powers, but it does not make the whole nervous organization hyperæsthetic, if I may so express it. Under this latter condition the nerves respond to the slightest stimulus, even that of a lively imagination, until it needs but a suggestion of discomfort in one part of the body to start reflex symptoms of the most acute type in another. There are certain affections of the female genitals which seem particularly liable to exert this baleful effect upon the whole nervous economy. Some of these have been recognized. Emmet long ago, and many others since then have pointed out the marked results in this direction of a neglected laceration of the cervix. After the primary symptoms of leucorrhœa, backache, dyspareunia, and a feeling of weight in the pelvis have persisted for a longer or shorter time, there are very apt to follow 
those phenomena which begin as nervous debility and end as nervous prostration, and theke latter symptoms may soon entirely predominate over the former.

This result is more apt to follow if in addition to the cervix the perineum is also lacerated.

Chronic pelvic cellulitis, of which we are hearing less and less, inasmuch as many cases which we formerly classed under this head, are now known to be affections of the tubes and ovaries, chronic metritis, and its result areolar hyperplasia, and even chronic endometritis, all furnish their contingent of neurasthenic cases.

Less, however, has been said about displacements as a cause, and yet I conceive that they not infrequently are the starting-point of grave nervous troubles and serve to keep it up. This cannot be said of all forms of displacement alike, and some consideration of the various malpositions of the uterus with reference to their significance in this respect, is of importance here.

Backward displacements of the uterus are by all means more serious than forward ones. The retroflexions and versions occur oftener, admit of a much greater degree of malposition, and with themselves dislocate other organs more than do the anteversions and flexions. The resulting disturbance to the blood and nerve supply is much more profound. Anteversions pure and simple are in my experience rare, and do not as a rule give rise to symptoms. When, however, with the anteversion there is some descent of the uterus as a whole, a combination which is by no means rare, the resulting effect upon the whole system is much more marked. The same may be said of anteflexion, though here symptoms referable to the bladder and back, and disorders of menstruation are much more common.

Retroversion of the uterus is the most common form of malposition that we meet with, and when of the first or second degree, that is, if the version is not more than one of $90^{\circ}$, it may often exist without symptoms. If the organ, however, is deflected from its normal position in which the long axis of the uterine body makes a right angle with the axis of the vagina, more than $90^{\circ}$, we have symptoms arising from pressure on the rectum, and are apt to have dislocation of other organs. The danger of neglecting the treatment of even the slighter degrees of this displacement lies, as I conceive it, in the fact that as the axis of the uterus approaches that of the vagina, the weight of the abdominal viscera comes directly upon the fundus, and the resistance to descent of the uterus being lessened, slight degrees of prolapse are likely to follow.

Retroflexion adds to the symptoms which it cuuses in common with the version, those due to the uterus itself being bent, either from a loss of tone of the muscular structure of the organ, or from being drawn over by adhesions. This flexion of the uterus is an exceedingly grave symptom, and productive of the most marked general disturbance. Both for this reason, and because its treatment is often difficult, requiring even severe operative measures for its relief, it is commonly regarded as perhaps the most serious displacement in the category.

Prolapse and procidentia follow closely on retroversion in frequency, and equal if not exceed it in importance. The severer forms of falling, especially when complicated with a rolling out of the anterior and posterior vaginal walls, cystocele and rectocele, are so easily recognized by both patient and physician that their true value as a cause of local and general symptoms is accorded them. Not so, however, with the milder forms, where either from increased weight, or a slight giving way of the natural supports, the uterus sinks a little lower in the pelvis. These relatively minor grades of displacements are very often passed by unheeded, when they in reality are a cause of constant and distressing symptoms. They are not recognized for the reason that in the ordinary method of examination they cannot be detected. With the patient in the dorsal position, the uterus, unless fixed, recedes from the vulvar orifice, and the examining finger fails to detect its abnormal mobility. Even if the patient is requested to strain, the action of the abdominal muscles is not sufficient to force the uterus as low as it descends when the patient is standing, and the force of gravity is added. 'The proper method of examining in these cases is with the patient standing in the erect position. Then if she is requested to contract the abdominal muscles as if to relieve the bowels, the finger in the vagina will appreciate the full amount of descent.

In the same category, though of less relative importance, are the displacements of the vaginal wall which may occur without any prolapse of the uterus, though their tendency is to produce such in time. They have only recently begun to receive the attention which they deserve.

Lateral displacements are merely subvarieties and minor complications of the forward and backward malpositions which we have spoken of, and do not need any special mention.

From the foregoing it will be seen that the displacements, which most often give rise to serious symptoms and demand treatment, are of the third degree or of lesser degrees when complicated with prolapse, retroflexion especially when bound down by adhesions and prolapse; less frequently anteflexion, anteversion with prolapse, and least frequently of all simple auteversion, and retroversion of the first two degrees.

If we study this order of relative frequency closely, it will be seen that there are three conditions upon which the gravity of the symptoms depends. First, prolapse; second, adhesions; and third, flexion. I have named them in this order because it seems to me that both as regards severity of local symptoms, and secondary effect upon the whole system, especially the nerves, that is the proper order of relative frequency and importance.

I am convinced that prolapse of the uterus, especially in its minor forms, has been much neglected or underestimated as a factor in the pathological significance of uterine displacements. A large proportion of anteversions give rise to no symptoms unless complicated with prolapse; the same is true of many cases of retroversion, and the symptoms complained of in these cases are those characteristic of a descent of the womb, and are relieved by the treatmentappropriate to that malposition. A slight amount of prolapse will cause more disturbance with the circulation than a very marked version, and the constant dragging and bearing down, which is the almost uuiversal com. plaint, is excessively wearing upon the nerves.

The detrimental effects of the presence of adhesions are shown in two ways: first, from the impairment of the mobility of the uterus which ensues; and second, 
the production of pain due primarily to the inflammation of the peritoneum, and secondarily to the implication of nerve filaments in the contracting bands of adhesions.

A bending of the uterus upon itself is of importance pathologically for several reasons. The two chief causes, however, to which its effects upon the general health are due, are the interference with the circulation in the organ itself, as a result of which alterations of tissue occur in time, and the displacement of other organs, notably the tubes and ovaries.

Having thus considered in a general way the various malpositions to which the uterus is liable, and the special circumstances connected with the different forms to which their pathological importance is due, it remains briefly to refer to their effect upon the system at large, and to iusist upon the necessity of treating them.

I do not by any means claim that uterine displacements are always the primary occurrence, and that they invariably cause grave nervous symptoms. On the contrary, there is that large class of cases of displacement from loss of tone of the uterine supports, where muscular debility is the first factor, and the uterine condition is merely one mode of expression of it. But, even in these cases, the continued presence of the pelvic trouble tends to keep up the condition of nervous debility, of which it may be originally only a symptom.

Of the three principal factors in these cases of displacement to which I have referred - flexions, adhesions, and prolapse - the importance of the first two is, I think, sufficiently recognized by the profession. The rôle they play in inducing and keeping up a state of nervous exhaustion is well known. The difficulty here is not that the necessity of treatment is not fully appreciated, but that they rank among the affections of the genital organs which are the most obstinate to yield to the ordinary methods.

Cases of flexions with adhesions were for a long time, and still are by some authorities, considered incurable, and it is the exceedingly unsatisfactory results of the methods of treatment which have been hitherto tried in a class of cases which entails so much local suffering and exercises such a deleterious effect upon the whole nervous system which has led to such severe operative measures being proposed and tried for their relief, as laparotomy, forcibly breaking up the adhesions, and stitching the fundus to the abdominal wall.

It is, however, different with prolapse, especially in the earlier stages. The importance of this has, I am confident, been under-estimated. I claim that is the one element which makes versions, which would otherwise give rise to no symptoms of any pathological significance. The constant feeling of weight in the pelvis, to which is soon added weakness of the muscles of the back and thighs, making locomotion painful, and standing even more difficult, is generally due either to the yielding of the muscular and ligamentous supports of the uterus, or the loss of the integrity of the pelvic floor as a result of parturition.

I would, therefore, urge in all cases where the lose of nervous tone is a prominent symptom, where headache, dyspepsia, inability to walk, sleeplessness following the least excitement, loss of mental power, as shown by the inability to concentrate the mind on any subject, loss of ability to control the emotions, evinced by fits of crying, depression, or temporary exaltation of spirits, followed by a corresponding reaction, where some or all of these symptoms are found, the careful consideration of the accompanying pelvic symptoms, and, if such exist, even though to a mild degree, would recommend a vaginal examination.

If any of the various malpositions be found which have been described in this paper, the important question has to be decided whether it should be treated, and when. If the history of the case makes it clear that it is the primary factor in the case, the first step should be the attempt to cure the pelvic trouble by treatment. The only exception to this rule is in those cases where the general health is so much reduced that the strain necessary to undergo local treatment would be too great. Here attempts must first be made to so improve the nervous condition by rest, food, and tonics, that treatment may be begun. The Weir Mitchell treatment, either thoroughly carried out or modified to suit the individual case, will serve as a model. In cases of this sort, if local treatment is entirely neglected, there may be improvement up to a certain point, but beyond that it will not advance if the special treatment of the genital complication is neglected.

Where the malposition is secondary, if taken in time, local treatment may sometimes be avoided. With the improvement in the condition of the geueral system, the uterus may recover itself. If it has persisted for some time, however, it in turn becomes one of the causes which keep up the depreciated state of the general health, and must be rectified before perfect health is restored. In these cases of profound nervous debility, every organ and function must be interrogated, and the ability to correctly estimate the pathological significance of the various departures from the normal conditions which are found, and the choice of the order and methods of treatment, is a matter requiring extreme delicacy and skill, and upon it depends the success of the physician.

As to the methods of treatment to be pursued, it is not the purpose of this paper to go into details. A few general considerations may be urged. Malpositions uncomplicated by adhesions or by inflammatory conditions in the pelvis, especially in unmarried women, may frequently be restored to their normal position and a pessary adjusted with a minimum of nervous strain to the patient at one sitting under ether. Where there are adhesions, or even in cases where there are not, but the vagina is narrow, the abdominal walls rigid, and the bimanual method of reposition difficult or impossible, the slower method, by packing the vagina, is to be recommended.

Where the uterus, on examination in the dorsal position, seems normal, but yet the patient complains of symptom which suggest some displacement, the examination in the erect posture for the slighter degrees of prolapse should not be neglected.

Of especial importance to my mind in this connection are slight tears of the perineum, impairing the integrity of the pelvic floor. These are often overlooked because they not infrequently occur either at the sides where they loosen the attachments of the pelvic fascia, or beneath the mucous membrane in the muscular structure of the perineal body, and the almost intact external perineum gives no evidence of the damage done. These changes, the result of parturition, are a fruitful source of prolapse of both uterus and vaginal 
walls, and their repair by a plastic operation will do much toward restoring the general health.

In the obstinate cases of retroflexion, where a pessary will not hold the uterus forward, the Alexander operation of shortening the round ligaments, or one of the other more serious operations, may be considered.

\section{HEBREW PHYSICIANS IN THE MIDDLE AGES.}

BY F. B. STEPHENSON, M.D., U. S. NAVY. Membre Titulaire de la Société d'Anthropologie de Paris.

From recently issued publications (Müuz, Hosmer) it appears that inmates of monasteries were not the only scholars that made the higher education of Greek and Arab the heritage of modern life. The work of the Jews in this direction is the more striking because of their political and social ostracism. Their personal worth, however, the value of their minds, could not be ignored by the intelligent; and in no field of thought have they won more fame, and thankful recognition among the Gentiles than in medicine. Theological views disappeared when human needs were felt. Pope and prince did not hesitate to follow the advice of Israelitish doctors. The poor were not neglected by them. They served as instructors to those about them. Both Orient and Occident honored them as men and as practitioners. Not only did these people produce an unusual proportion of good surgeons to practice current methods, but through them, at the Renaissance, medicine was revived, to become the parent of physical science in general. In the composite picture presented, we notice a few prominent traits.

Isaac Israeli (obit 950), was a renowned practitioner, and his work "De Diatetica," published among the Arabs, mav claim to be of decided value even now. He lived to be 110 years of age, and when asked why he had never married, replied "I have written four books, which will preserve remembrance of me better than children."

Maimonides, ${ }^{1}$ in his epistle to the luxurious Sultan, in Egypt, while prescribing for the body, dared to direct the mind toward a rational living.

One ambitious son of Israel, however, a famous doctor, turned Mahommedan; but this change did not bring the desired reputation in a community hostile to those of his original faith; his last days were not peaceful. Another learned one became prime minister of the Great Khan, at Bagdad, and used his power to advance all branches of knowledge; yet envy and illwill worked his fall. The popular hate toward this race was then (1291 A. D.) the cause of death to many thousands, jealousy, as in our day, being the apparent motive. Moslem physicians generally understood more of astrology and magic then of the noble art of healing, although the Jews, also tried to guide human conduct by stellar positions.

The Hebrew court physicians among the Spanish Arabs did much to preserve and transmit to modern central and western Europe the medical lore of ancient Greece and Rome, though little actual progress in natural or morbid physiology appears to have been made and recorded by them. The contemporary Christian rulers in the peninsula, despite their catholicity, prized the wise sons of David not less than

1 Dr. Münz, affirming that the industry of Maimonides, as a practitioner and writer of authority in professional matters, has not been justly shown, states his intention to publish a paper thereon. did their Moorish cousins. At the same time, the common folk, similarly to the Islamitic masses, persecuted the "peculiar people,". for both religious and economic reasons. A Hebrew surgeon persuaded John II, of Portugal, to refuse aid to Columbus when he asked ships for his royage of discovery. Cohen and Halevi are names famous for learning and virtue.

Toward the end of the 15 th century, a most sad tragedy drove the Judaic people, and with them the physicians, from Spain and Portugal; so that those who, about that time needed a surgeon, were left to the care of quacks and impostors, or found themselves forced to send, at great cost, to distant lands.

Touching central Europe, it is well-known (says Livius Fürst) that, from Charlemagne to Francis First (who requested Charles the Fifth to send him an Israelitish doctor) every ruling prince had a Hebrew as personal physician. The one with Charles the Bald had such a name for magic and witchcraft, that common report credited him with having swallowed up a wagon laden with hay, together with team and driver. Although less advanced and progressive than those of Spain, yet Jewish physicians throughout Germany were fit to be called learned when compared with their Christian colleagues, who knew little of remedial science, and were sunk in ignorance and superstition.

In Ratisbon the inimical citizens complained that almost everybody allowed Israelites to attend them. In various parts of centräl Europe, from Könisbèrg (where in 1538, it was unlawful for such to practice) to Strassburg, Hebrew doctors were among those who were first excused from onerous taxes. Import duties on medical books and surgical instruments do not appear as exceptions from such franchise. Will the United States be flattered by comparison?

In Vienna they could not, at one time, be practitioners because of their inability to subscribe to the customary oath, "de immaculata conceptione:" in 1517, however, the emperor abrogated this rule. At different times (1373-1567), and in various places throughout Germany, city physicians were employed with definite honoraria. During the 15th century, Jewish women were successful in medicine. In 1419, one received official recognition from the government : about 1430, another was a skilful oculist. Similar instances were not rare, among the Teutons. The renowned John Reuchlin had two Hebrew scholars and physicians as friends and instructors.

In France we find a comparatively larger and more brilliant series of medical men, some of whom possessed the favor and protection of sovereigns, from Hugh Capet to Maria di Medici. Numbers of them were eminent scholars in science, and the ancient literature of physic (translating from Arabic), as well as instructors in medicine to many pupils of the Christian faith, together with those of their own racial descendance.

'The Montpellier school, so flourishing in the first half of the thirteenth century, was in great part founded and sustained by them. Nevertheless, one illustrious son of Abraham, in 1288, became a victim of the auto de fé, and several were tortured to death on false charges of poisoning.

When, in 1453, the crescent rose above the cross in Constantinople, skill and prudence caused the Hebrew doctors to be trusted and honored by those in power. The influence thus gained was often used to lighten 